\title{
RESENHA
}

\section{Introdução à análise qualitativa comparativa e aos conjuntos Fuzzy (fsQCA)}

\begin{abstract}
BETARELLI JUNIOR, Admir Antonio; FERREIRA, Sandro de Freitas. Introdução à análise qualitativa comparativa e aos conjuntos Fuzzy (fsQCA). Brasília: Enap, 2018. Disponível em: repositorio.enap.gov.br. (Coleção Metodologias de Pesquisa).
\end{abstract}

\section{Clayton Mendonça Cunha Filho Universidade Federal do Ceará, Brasil (i) https://orcid.org/0000-0001-6073-3570 cunhafilho@ufc.br}

Embora proposta inicialmente ao final dos anos 1980 por Charles Ragin (1989) e ganhando cada vez maior aceitação e desenvolvimentos metodológicos ao redor do mundo desde então, as técnicas de análise configuracional baseadas na teoria de conjuntos, popularmente conhecidas como QCA, ainda são, com algumas poucas exceções, largamente ignoradas pela academia brasileira. Um dos motivos 
certamente tem a ver com o nosso “calcanhar metodológico” apontado por Gláucio Soares (2005): o treinamento em metodologia de pesquisa nas graduações brasileiras é, em geral, fraco e encontra-se marcado por um estéril debate entre quantitativistas e os adeptos de metodologias qualitativas, onde via de regra os quanti rejeitam qualquer outra possibilidade metodológica fora da estatística, enquanto os quali frequentemente o são apenas pela negação aos métodos quantitativos, sem de fato buscarem compreender ou refletir acerca das premissas metodológicas de seu trabalho de maneira mais formalizada. Mas uma das causas desse calcanhar provavelmente tenha a ver com a escassez de bons livros-texto metodológicos em português, sejam eles produções próprias ou traduções de manuais consagrados, o que dificulta enormemente seu ensino na maioria das graduações do país devido à barreira linguística. Nesse sentido, é extremamente bem-vinda a contribuição de Admir Betarelli Jr. e Sandro Ferreira com o pequeno livro Introdução à análise qualitativa comparativa e aos conjuntos Fuzzy (fsQCA), publicado em 2018 pela Escola Nacional de Administração Pública (Enap) e disponibilizado gratuitamente através da internet.

Bastante sucinto e direto ao ponto, o livro inicia recapitulando a origem e o desenvolvimento das técnicas de análise qualitativa comparada (QCA, na sigla em inglês) e seu robustecimento com a incorporação dos conjuntos fuzzy a partir dos anos 2000, sua adoção ao redor do mundo e seu virtual desconhecimento no Brasil, com a citação de alguns dos poucos pioneiros nacionais, como Sandes-Freitas e Bizzarro-Neto (2016) e a listagem dos softwares existentes para aplicação da técnica. Mas, por se tratar de texto introdutório inicial, possivelmente a primeiríssima entrada de muitos nesta literatura, os autores dedicam a maior parte do livro à explicação dos fundamentos teórico- 
epistemológicos em que se baseia a QCA, com apenas o quarto e último capítulo (p. 105-24) dedicado a duas breves exemplificações de sua aplicação técnica.

Assim, no capítulo 1, intitulado “Afinal, o que a QCA trata?”, Betarelli Jr. e Ferreira explicam seus fundamentos na teoria matemática dos conjuntos e na lógica booleana, onde os conceitos são trabalhados como sendo um conjunto que abriga os casos determinados a partir de seu pertencimento ou ausência, e apresentando algumas implicações epistemológicas do método e seus termos técnicos mais recorrentes. Os fenômenos a serem investigados são eles também tratados como um conjunto ao que se pertence ou não, de forma dicotômica na QCA original ou parcial em sua versão fuzzy, e que resultam da interação em configurações complexas dos outros conjuntos, chamados de condições. Ao mesmo tempo uma forma de conceituar fenômenos e uma técnica de análise, a QCA busca, através da lógica, indicar as relações de necessidade e/ou suficiência entre as distintas configurações de condições e o conjunto resultado, sendo a fase de delimitação teórica e calibração dos conjuntos a parte mais demorada e trabalhosa do método. Os autores traçam ainda, nesse capítulo, um pequeno comparativo entre as aplicações de QCA e de métodos estatísticos, tentando mostrar os diferentes jargões utilizados por uns e outros em suas similitudes, mas sempre com o cuidado de ressaltar as particularidades da QCA a fim de evitar maiores equívocos por um paralelismo excessivo entre os dois mundos. E encerram o capítulo com uma breve revisão bibliográfica do estado da arte atual na matéria.

Em seguida, os autores dedicam o segundo e mais extenso dos capítulos (p. 37-78) a apresentar a teoria de conjuntos em que se baseia a técnica, tanto em sua concepção dicotômica (crisp-set) quanto na difusa (fuzzy-set), em que se admite o pertencimento parcial em gra- 
dações dos casos aos conjuntos, e as implicações lógico-matemáticas do pertencimento a conjuntos, subconjuntos, superconjuntos, intersecções e disjunções que permitem à QCA, enquanto técnica analítica, estabelecer relações de necessidade e/ou suficiência entre os mesmos. Embora qualitativa, a metodologia envolve certa formalização matemática que, se por um lado pode afastar certo leitor quali do calcanhar de Gláucio Soares, também pode, por outro, diminuir certa resistência do leitor quanti do mesmo calcanhar, contribuindo para tecer algumas pontes entre os dois grupos. Mas, por utilizar álgebra booleana e não matricial e cálculo como nos métodos estatísticos, pode também confundir inicialmente o público quanti na medida em que símbolos matemáticos clássicos como + ou * adquirem significado distinto enquanto operadores lógicos booleanos, equivalendo o primeiro à disjunção "OU” e o segundo à conjunção “E”, e que as configurações causais escritas de forma semelhante a equações matemáticas não têm, aqui, o mesmo significado. Especialmente na versão fuzzy, compreender as propriedades dos operadores lógicos, que não representam a soma ou a multiplicação dos valores dos conjuntos, mas sim a adoção do valor máximo ou mínimo dentre eles, é fundamental para o êxito analítico e os autores utilizam-se exitosamente de figuras, gráficos e tabelas a fim de ilustrar os princípios lógicos envolvidos.

Antes de proceder no capítulo quatro à exemplificação da técnica, primeiro com um trabalho próprio, depois com um estudo selecionado de outros autores, Betarelli Jr. e Freitas dedicam o terceiro capítulo a apresentar os procedimentos para construção do elemento que compõe o núcleo analítico central da técnica, a Tabela Verdade (Truth Table). Aparentemente idêntica a uma matriz de dados para análise estatística, a Tabela Verdade difere desta por representar em cada linha, em vez de um caso empírico concreto, cada uma das $2^{\mathrm{k}}$ possibilidades 
combinatórias dentre as condições elencadas para análise e a quantidade de casos concretos contidos em cada uma delas. Conforme mencionado, a delimitação e construção dos conjuntos de condições consideradas teoricamente relevantes para o fenômeno estudado consiste na etapa mais demorada e dispendiosa de uma QCA, sendo a construção da Tabela Verdade um dos últimos - embora crucial - passos da pesquisa. Mas é na construção da Tabela Verdade que se permite finalmente proceder à análise das relações entre os conjuntos ou perceber potenciais problemas entre eles, que por sua vez podem implicar novos esforços de reconstrução e delimitação dos conjuntos originais de condições.

Uma das principais riquezas dessa abordagem metodológica reside precisamente nesse processo iterativo de construção dos conjuntos para análise com base na teoria envolvida e no conhecimento profundo dos casos englobados, não se tratando o método de um mero apertar botões e analisar resultados. Dificilmente chega-se a uma Tabela Verdade limpa e sem quaisquer problemas, visto que a quantidade de combinações lógicas possíveis (linhas na tabela) cresce exponencialmente a cada condição acrescentada e inexoravelmente o pesquisador se deparará com o problema da diversidade limitada e dos remanescentes lógicos, isto é, combinações teoricamente possíveis de configurações, mas que não possuem nenhum exemplo empírico no mundo real. Os autores apresentam algumas das soluções possíveis com base nas “melhores práticas” de aplicação do método consolidadas até o momento, mas sempre enfatizando o fato de que não há soluções automáticas e que dependerão do “diálogo” pesquisador-teoriacasos as possíveis soluções ao impasse.

Em suma, o livro constitui uma introdução muito útil à análise comparativa baseada em conjuntos e poderá ser ferramenta inestimá- 
vel a professores de metodologia comparada em cursos de graduação impossibilitados de recorrer a livros-texto em inglês. Àqueles desejosos de aprofundamento no método, os autores enumeram no livro os melhores manuais disponíveis em língua estrangeira, e é mesmo uma pena que estes não tenham ainda despertado interesse de tradução em nenhuma de nossas editoras acadêmicas. Algo que - esperamos! poderia vir a mudar no futuro a partir do interesse despertado na comunidade acadêmica brasileira a partir de boas introduções como esta e da difusão cada vez maior no país de boas e variadas escolas de verão e inverno em metodologia que incluem frequentemente módulos de QCA em suas ofertas.

\section{Referências}

RAGIN, Charles C. The Comparative Method: Moving Beyond Qualitative and Quantitative Strategies. Paperback ed. Berkeley: University of California Press, 1989.

SANDES-FREITAS, Vitor; BIZZARRO-NETO, Fernando. Qualitative Comparative Analysis (QCA): usos e aplicações do método. Revista Política Hoje, v. 24, n. 2, p. 103-118, 12 jan. 2016.

SOARES, Gláucio Ary Dillon. O calcanhar metodológico da ciência política no Brasil. Sociologia, n. 48, p. 27-52, maio 2005. 


\title{
Resumo:
}

Resenha de BETARELLI JUNIOR, Admir Antonio; FERREIRA, Sandro de Freitas. Introdução à análise qualitativa comparativa e aos conjuntos Fuzzy (fsQCA). Brasília: Enap, 2018. (Coleção Metodologias de Pesquisa).

Palavras-chave: QCA; fuzzy-sets; metodologia qualitativa comparada.

\begin{abstract}
:
Book review from BETARELLI JUNIOR, Admir Antonio; FERREIRA, Sandro de Freitas. Introdução à análise qualitativa comparativa e aos conjuntos Fuzzy (fsQCA). Brasília: Enap, 2018. (Coleção Metodologias de Pesquisa).
\end{abstract}

Keywords: QCA; fuzzy-sets; qualitative comparative methodology. 